Jun Seok

Jong-Chun Park*

$\underline{\text { http://dx.doi.org/10.21278/brod71104 }}$

ISSN 0007-215X

eISSN 1845-5859

\title{
A FUNDAMENTAL STUDY ON MEASUREMENT OF HULL ROUGHNESS
}

UDC 629.5.015.2:629.541.2:629.331

Professional paper

\begin{abstract}
Summary
In this study, an investigation on the hull roughness measurement of a new ship, a $160 \mathrm{~m}$ class car ferry, was performed. The hull roughness measurement was conducted in the ferry's pre-coated state before launching. For measurement, the TQC manual and ITTC recommendations were considered, and measurements were made in a total of 230 zones below waterline of the ship. Accordingly, the average hull roughness of the car ferry was $81 \mu \mathrm{m}$, which is relatively low compared to $150 \mu \mathrm{m}$, the hull roughness of a new ship proposed by the ITTC. In addition, the measurement uncertainty was calculated using the ISO guidelines, and the effect of the number of zones on the hull roughness measurement was examined. Using the measured average hull roughness, we estimated the resistance performance at the design speed of the ship. Accordingly, it was confirmed that the total resistance of the new ship was reduced by approximately $2 \%$ owing to a decrease in its frictional resistance increase.
\end{abstract}

Key words: $\quad$ Hull roughness; Measurement; New ship; Resistance; Uncertainty

\section{Introduction}

According to the International Maritime Organization (IMO) report, as presented in Table 1, between 2007-2012, the average carbon dioxide $\left(\mathrm{CO}_{2}\right)$ emission from shipping and international shipping of vessels accounts for $3.1 \%$, and $2.6 \%$ of the global emission ([1]).

IMO implements environmental regulations such as the energy efficiency design index (EEDI) and energy efficiency Operational Indicator (EEOI) on ships to reduce carbon dioxide emissions, one of the causes of global warming. In particular, the EEDI is mandatory for new vessels carrying more than 400 gross tonnage and is gradually increasing its restriction until 2025. 
Table 1 Amount of $\mathrm{CO}_{2}$ emission from shipping

\begin{tabular}{|c|c|c|c|c|c|}
\hline Year & $\begin{array}{c}\text { Global CO } \\
\text { (million } \\
\text { tonnes) }\end{array}$ & $\begin{array}{c}\text { Shipping } \\
\text { (million } \\
\text { tonnes) }\end{array}$ & $\begin{array}{c}\text { Portion of } \\
\text { shipping } \\
(\%)\end{array}$ & $\begin{array}{c}\text { International } \\
\text { shipping } \\
\text { (million } \\
\text { tonnes) }\end{array}$ & $\begin{array}{c}\text { Portion of } \\
\text { International } \\
\text { shipping } \\
(\%)\end{array}$ \\
\hline 2007 & 31,409 & 1,100 & 3.5 & 885 & 2.8 \\
\hline 2008 & 32,204 & 1,135 & 3.5 & 921 & 2.9 \\
\hline 2009 & 32,047 & 978 & 3.1 & 855 & 2.7 \\
\hline 2010 & 33,612 & 915 & 2.7 & 771 & 2.3 \\
\hline 2011 & 34,723 & 1,022 & 2.9 & 850 & 2.4 \\
\hline 2012 & 35,640 & 938 & 2.6 & 796 & 2.2 \\
\hline Average & 33,273 & 1,015 & 3.1 & 846 & 2.6 \\
\hline
\end{tabular}

Shipyard and ship owners are applying various methods in the building and operating stages to satisfy the above environmental regulations.

The performance of a ship is improved by optimizing its linearity or installing an appendage in the construction stage of the ship to reduce its resistance. In addition, the oil consumption is reduced by optimizing the seaway of a ship during its operation stage, and a periodic hull cleaning minimizes the increase in the hull roughness during sailing to reduce the frictional resistance.

The hull roughness of a new ship is defined as $150 \mu m([2])$ if no separate measurement data are available, and it increases over time. However, the amount of increase depends on the type of paint ([3]). In general, the hull roughness is increased owing to the occurrence of fouling phenomena such as barnacles or slime over time.

To suppress such fouling, efforts are being made to reduce the amount generated by using anti-fouling paints or silicone foul release paints, but these do not provide complete prevention. Therefore, a ship-owner monitors the condition of the ship and decides its cleaning plan to keep the ship clean through periodic hull cleaning.

As such, studies in relation to hull roughness have been performed using various approaches. Experimental approaches are mainly based on basin experiments using a plate ([4][5]). In recent years, there have been an increasing number of studies on ships using numerical simulation methods ([6]-[15]).

However, the research on hull roughness measurement is relatively insignificant, and the hull roughness is partly measured according to the methods presented by the ship paint or instrument company. This is because the measurement of the hull roughness of a ship is not an essential requirement for the construction of a ship and the focus is on the paint thickness, which can affect the corrosion of the ship rather than the hull roughness due to the coating.

So in this paper, a study on the measurement of hull roughness is performed that has not been studied extensively to evaluate effect of roughness for frictional resistance. 


\section{Hull roughness measurement}

\subsection{Hull roughness measuring instrument}

The instrument used to measure the hull roughness is the Hull Roughness Analyzer DC9000 model manufactured by the TQC company as shown in Fig. 1. This model can measure the surface roughness $\left(R_{t}\right)$ based on the measurement length using a physical measurement sensor, and its specifications are listed in Table 2 (TQC [16]).

The measurement value $R_{t}$ is the peak-to-valley value, which is the difference between the maximum value and minimum value in the measurement interval, and for the ship, the value measured in a 50-mm-interval is used, which is denoted as $R_{t(50)}$.

The measured $R_{t}$ value can be expressed as the mean hull roughness $(M H R)$ of a zone, as given in eq. (1), and the instrument generally uses the average of twelve $R_{t(50)}$ values. The average hull roughness $(A H R)$, which represents the hull roughness of a ship, is the mean value of the $M H R$, as given in eq. (2), and can be weighted.

$$
\begin{aligned}
M H R & =\frac{1}{n} \sum_{i=1}^{n} R_{t(50) i} \\
A H R & =\frac{\sum_{j=1}^{m}(M H R)_{j}}{\sum_{j=1}^{m} w_{j}}
\end{aligned}
$$

Here, $\mathrm{n}$ is the number of measurements, $\mathrm{m}$ is the number of measurement points, and $w$ is a weight function, typically 1.

Table 2 Specifications of DC-9000

\begin{tabular}{|c|c|}
\hline Item & Data \\
\hline Memory capacity & 4000 series of measurements \\
\hline Sensor depth & $205 \mathrm{~mm}$ \\
\hline Sensor width & $80 \mathrm{~mm}$ \\
\hline Sensor height & $40 \mathrm{~mm}$ \\
\hline Sensor weight & approx. $630 \mathrm{~g}$ \\
\hline Accuracy & \pm 5 microns or $<2 \%$, whichever is greater \\
\hline
\end{tabular}




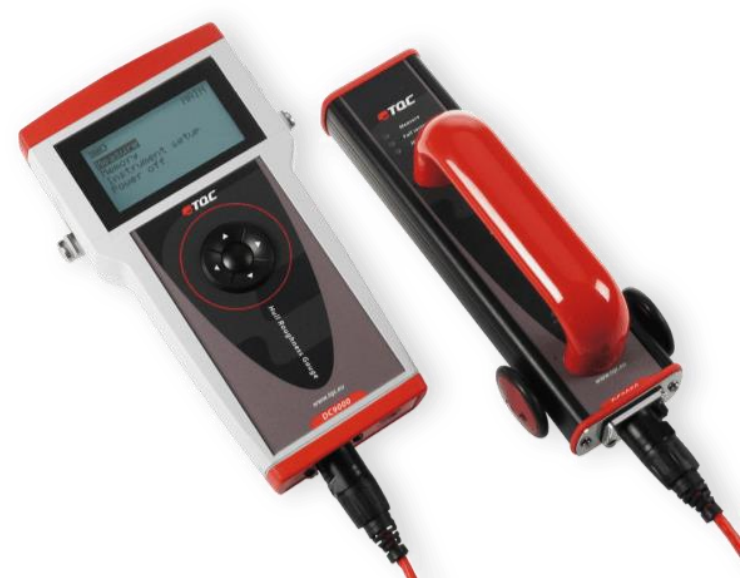

Fig. 1 Hull roughness gauge (DC-9000)

\subsection{Hull roughness measuring method}

The target vessel for measuring the hull roughness is a $160 \mathrm{~m}$ class car ferry, as shown in Fig. 2, and its specifications are listed in Table 3.

Table 3 Principal particular of $160 \mathrm{~m}$ class car ferry

\begin{tabular}{|c|c|}
\hline Item & Dimensions \\
\hline Length Over All & $160.0 \mathrm{~m}$ \\
\hline $\begin{array}{c}\text { Length Between } \\
\text { Perpendiculars }\end{array}$ & $148.0 \mathrm{~m}$ \\
\hline Breadth & $24.8 \mathrm{~m}$ \\
\hline Design Draft & $5.5 \mathrm{~m}$ \\
\hline
\end{tabular}

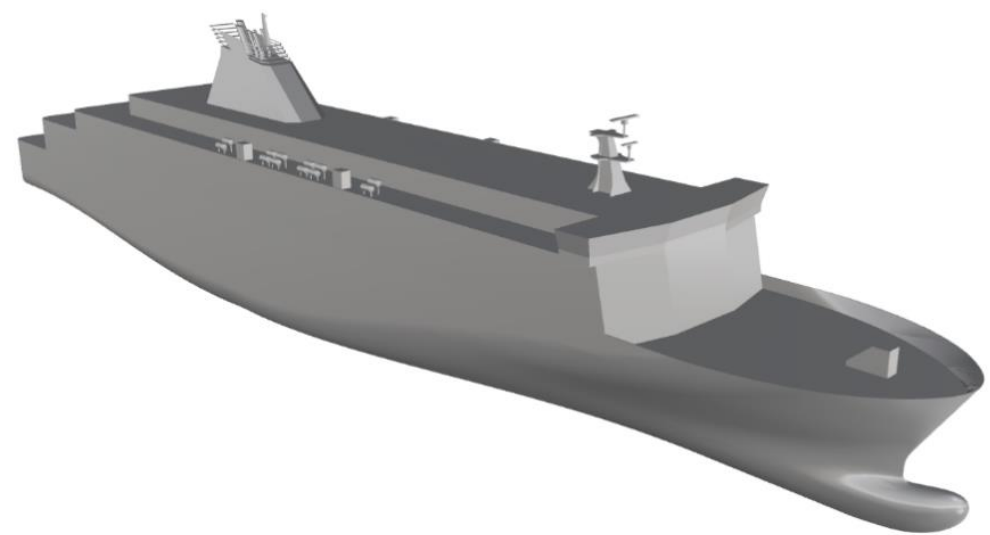

Fig. 2 Three-dimensional model of the ship

Measuring process of hull roughness is divided into three step as shown in Fig. 3.

In the first step, it is necessary to arrange the zones before the measurement to measure the hull roughness. For the measurement zones, it is recommended to measure more than 100 zones in the side area (Port \& Starboard) and bottom area under the draft, and to measure at least thrice at the measurement points ([16]-[17]). In this study, as shown in Fig. 4, the 
measurement is performed in a total of 230 zones, with 51 zones in the port and starboard area each and 128 zones in the bottom area.

In the next step, measuring instrument should be calibrated using calibration plate as shown in Fig. 5 just before measurement. Also set the measuring length of $R_{t}$. After measurement, send the measuring data to PC and calculating the $M H R$ and $A H R$.

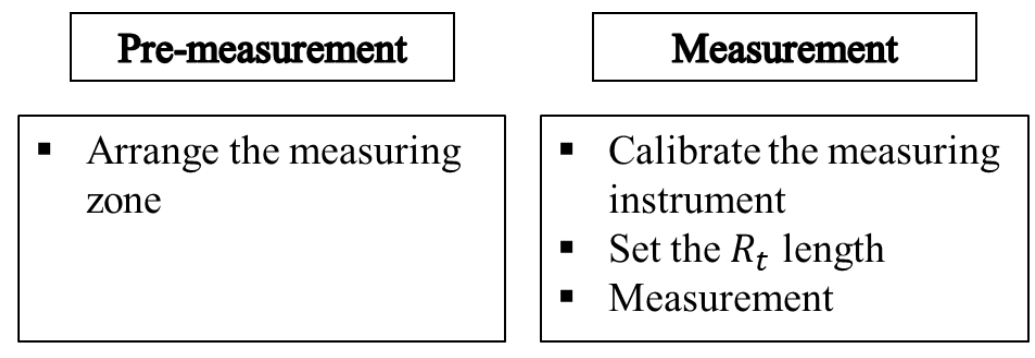

\section{Post-measurement}

Fig. 3 Measurement process of hull roughness

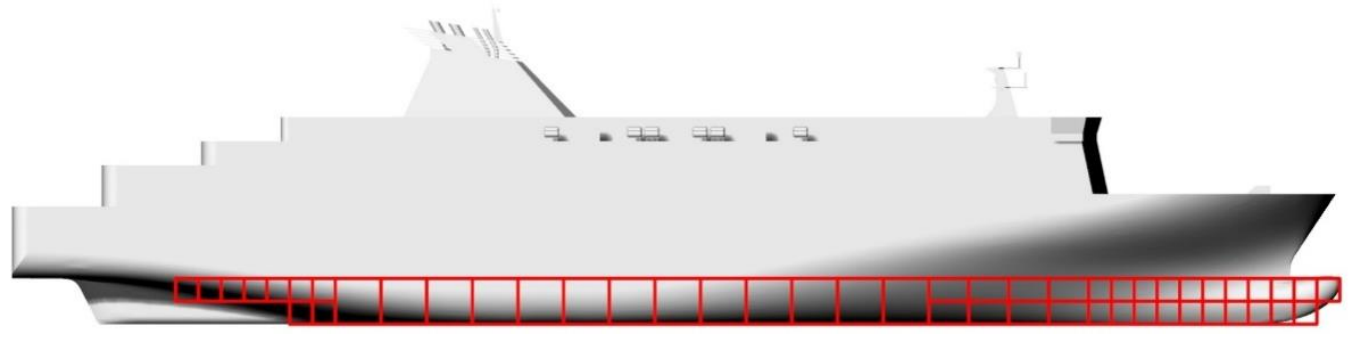

(a) Side (Port and Starboard)

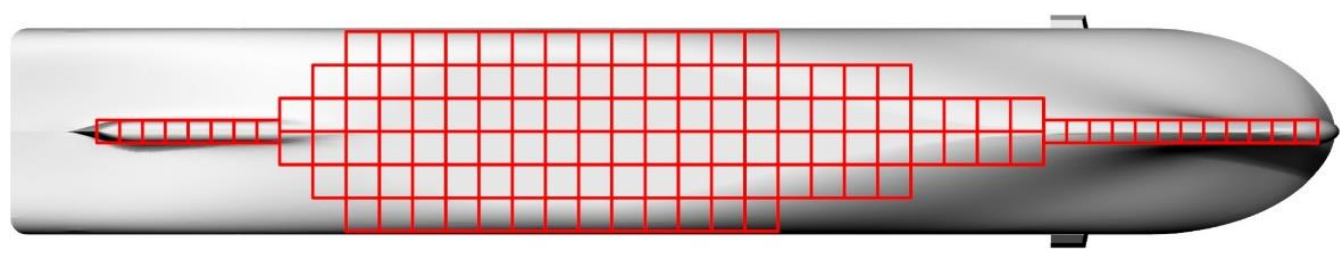

(b) Bottom

Fig. 4 Measurement zones for the hull roughness

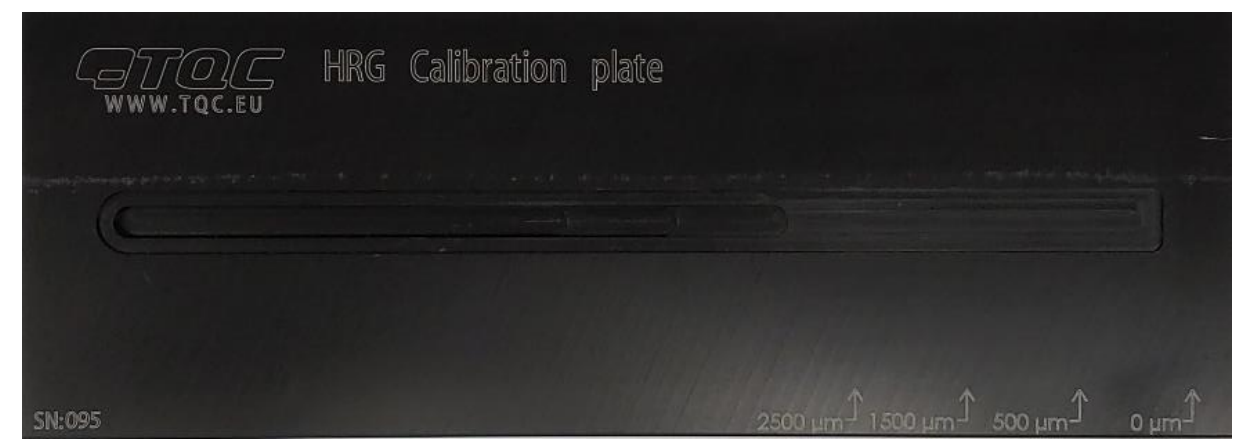

Fig. 5 Calibration plate of hull roughness gauge(DC-9000) 


\section{Measurement result}

As shown in Fig. 6, the measurement of the ship was performed on the floating dock, with the final painting completed before launching, using a mobile crane in the side area. The calibration of measurement instrument was performed according to the manual before measurement. The measurement was performed by two personnel for measuring the bottom area and side area and took approximately 4 hours.
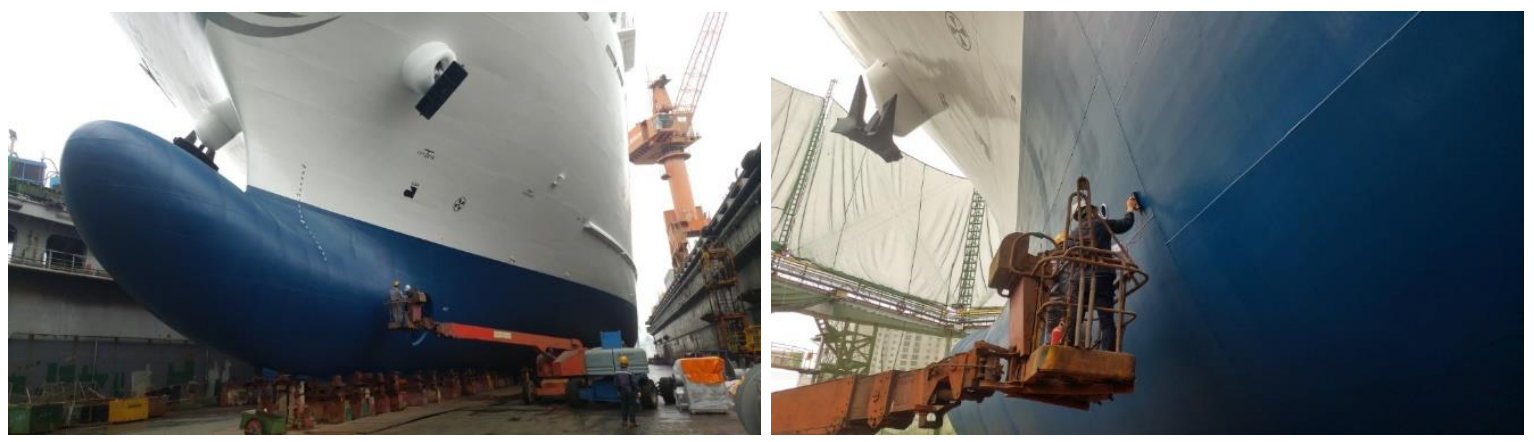

Fig. 6 Measurement of hull roughness

The measurement results are shown in Fig. 7 and summarized in Table 4.

The minimum value of the $R_{t(50)}$ measured in the port area is $23 \mu \mathrm{m}$ and maximum value is $386 \mu m$. Using the results of ten $R_{t(50)}$ values, excluding the maximum and minimum values in each zone, the minimum $M H R$ is $51 \mu \mathrm{m}$ and maximum $M H R$ is $241 \mu \mathrm{m}$. In this case, the zones where the maximum and minimum values are measured are shown in Fig. 8 (a).

The minimum value of the $R_{t(50)}$ measured in the starboard area is $19 \mu \mathrm{m}$ and maximum value is $384 \mu \mathrm{m}$. Based on the measured results, the minimum and maximum $M H R$ is $51 \mu \mathrm{m}$ and $241 \mu \mathrm{m}$, respectively, when calculating the $M H R$ for the port area. In this case, each zone where the maximum and minimum values are measured is shown in Fig. 8 (b).

The minimum value of the $R_{t(50)}$ measured in the bottom area is $16 \mu \mathrm{m}$ and maximum value is $317 \mu \mathrm{m}$, which are relatively small compared to the results of the side areas (port and starboard). The minimum $M H R$ is $38 \mu \mathrm{m}$, and the maximum $M H R$ is $214 \mu \mathrm{m}$. This is because the bottom area is relatively flat compared to the side areas. At this time, each zone where the maximum and minimum values are measured is shown in Fig. 8 (c).

The $A H R$ using the $M H R$ of each zone is $101 \mu \mathrm{m}$ for the port area and $81 \mu \mathrm{m}$ for the starboard area, showing that that the latter is approximately $20 \%$ lower than that of the former. Additionally, the bottom area has an $A H R$ of $73 \mu \mathrm{m}$, which is approximately $20 \%$ lower than the average of $91 \mu \mathrm{m}$ for the side area. Finally, the $A H R$ of the $160 \mathrm{~m}$ class car ferry, obtained by combining the results of the side area and bottom area, is $81 \mu \mathrm{m}$. Although this value is approximately $46 \%$ lower than the ISO-based $150 \mu \mathrm{m}$ hull roughness of a new ship, it is still within the range of $80-150 \mu m$ as suggested by Hudson et al. [18] for the hull roughness of a new ship.

Table 4 Summary of the hull roughness measurement

Area
Roughness $(\mu m)$ 


\begin{tabular}{|c|c|c|c|c|c|}
\hline & $\begin{array}{c}\text { Minimum } \\
R_{t(50)}\end{array}$ & $\begin{array}{c}\text { Maximum } \\
R_{t(50)}\end{array}$ & $\begin{array}{c}\text { Minimum } \\
M H R\end{array}$ & $\begin{array}{c}\text { Maximum } \\
M H R\end{array}$ & AHR \\
\hline \multirow{2}{*}{ Port } & $\begin{array}{c}23 \\
(\mathrm{P}-49)\end{array}$ & $\begin{array}{c}386 \\
(\mathrm{P}-46)\end{array}$ & $\begin{array}{c}51 \\
(\mathrm{P}-18)\end{array}$ & $\begin{array}{c}241 \\
(\mathrm{P}-47)\end{array}$ & 101 \\
\hline \multirow{2}{*}{ Starboard } & 19 & $\begin{array}{c}384 \\
(\mathrm{~S}-44)\end{array}$ & $\begin{array}{c}34 \\
(\mathrm{~S}-41)\end{array}$ & $\begin{array}{c}212 \\
(\mathrm{~S}-21)\end{array}$ & 81 \\
\hline \multirow{2}{*}{ Bottom } & 16 & 317 & 38 & 214 & 73 \\
\hline Total & $(\mathrm{B}-85)$ & $(\mathrm{B}-122)$ & $(\mathrm{B}-54)$ & $(\mathrm{B}-122)$ & 73 \\
\hline
\end{tabular}

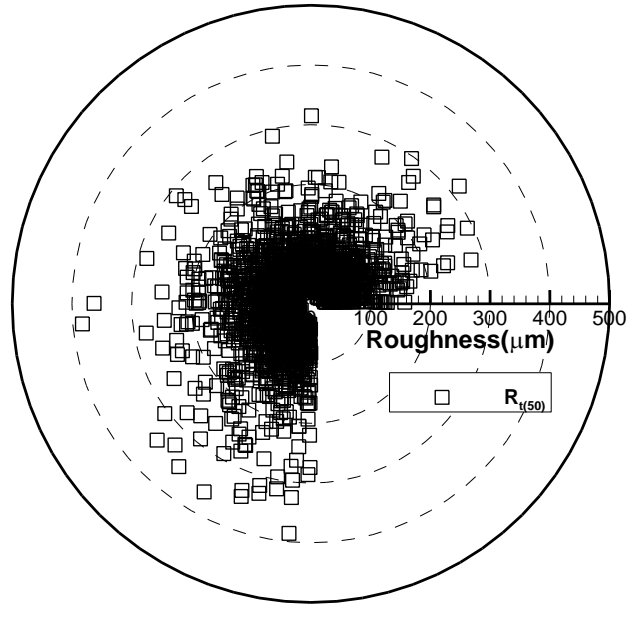

(a) $R_{t}$

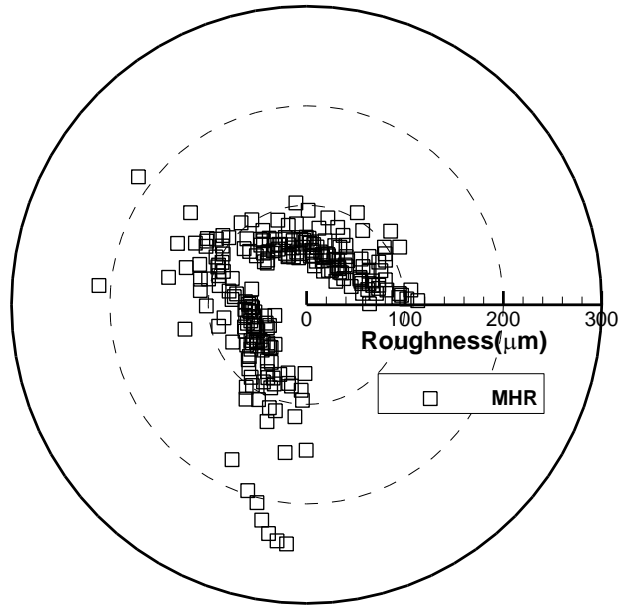

(b) $M H R$

Fig. 7 Results of the hull roughness measurement

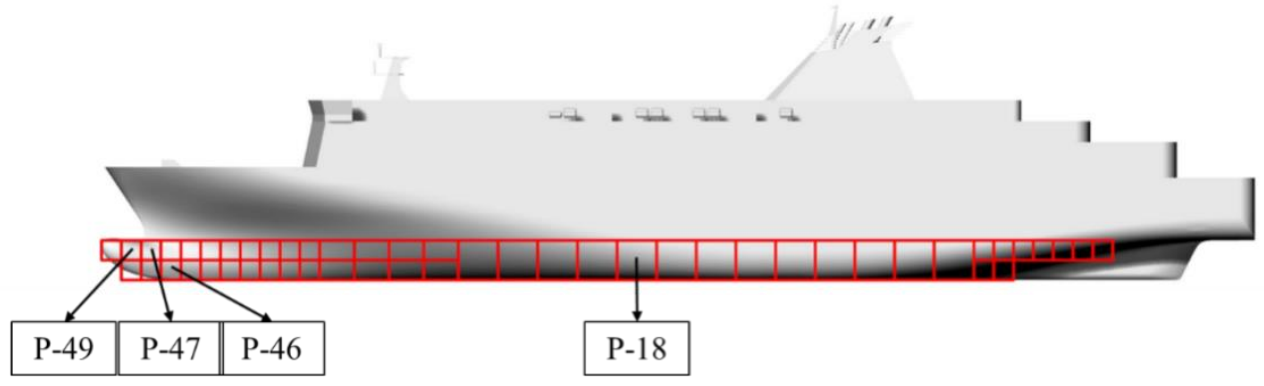

(a) Port

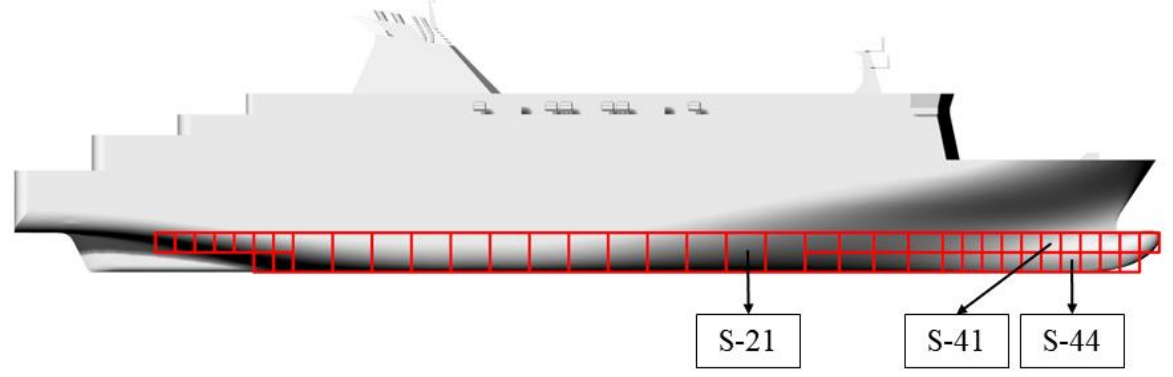


(b) Starboard

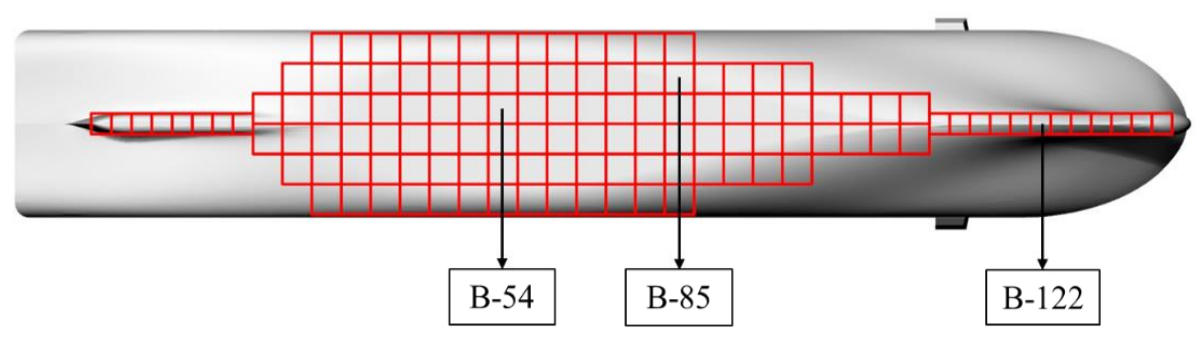

(c) Bottom

Fig. 8 Location of the maximum and minimum

To confirm the reliability of the measurement results, a measurement uncertainty analysis was performed according to ISO guidelines ([19]).

The measurement uncertainty was calculated by applying two evaluation methods. The A-type evaluation method calculates the standard uncertainty by statistically processing the measurement results using the data from repeated measurements. The B-type evaluation method calculates the standard uncertainty by using specifications of the measurement equipment. Here, the accuracy of the instrument used in calculating the B-type standard uncertainty was $\pm 5 \mu \mathrm{m}$ as specified in Table 2 and the standard uncertainty was calculated assuming a rectangular distribution.

For each calculation, the A-type standard uncertainty is $2.356 \mu \mathrm{m}$ and B-type standard uncertainty is $2.887 \mu \mathrm{m}$. The standard uncertainty of each is obtained using the root sum square method (RSSM), and the combined standard uncertainty (C.S.U) is also calculated by eq. (3).

The expanded uncertainty is calculated assuming a 95\% confidence level $(\mathrm{k}=2)$ for the final obtained standard uncertainty, and the result is $7.453 \mu \mathrm{m}$. Therefore, the $A H R$ of the $160 \mathrm{~m}$ class car ferry, which is measured in this study, is $81 \pm 8 \mu \mathrm{m}$ considering the measurement uncertainty.

$$
\text { C.S.U }=\sqrt{a^{2}+b^{2}}
$$

In addition, to determine the effect of the number of zones, $A H R$ was calculated using arbitrary 50,100, 150, and 200 zones out of $230 M H R$ data. For this, a random function was used for the data extraction, and data was extracted 100 times in each case.

As shown in Table 5, the minimum $A H R$ increases and maximum $A H R$ decreases as the number of $M H R$ increases from 50 to 100 . However, when the number of zones is more than 100 , the variation is not significant, and tends to converge. Therefore, to ensure the accuracy of the measurement results, 50 zones are not sufficient, instead at least 100 zones should be measured.

Table 5 Evaluation results with MHR number

\begin{tabular}{|c|c|c|c|}
\hline Number of $M H R$ & $\begin{array}{c}\text { Minimum } A H R \\
(\mu \mathrm{m})\end{array}$ & $\begin{array}{c}\text { Maximum } A H R \\
(\mu \mathrm{m})\end{array}$ & $\begin{array}{c}\text { Average } \\
(\mu \mathrm{m})\end{array}$ \\
\hline 50 & 70 & 92 & 80 \\
\hline
\end{tabular}




\begin{tabular}{|l|l|l|l|}
\hline 100 & 75 & 90 & 81 \\
\hline 150 & 76 & 88 & 81 \\
\hline 200 & 75 & 88 & 81 \\
\hline
\end{tabular}

The measured hull roughness results were used to estimate the resistance performance at the designed speed. For the resistance estimation, a frictional resistance estimation method considering the hull roughness of the ITTC-57 method and Townsin [20] is used as expressed in eq. (4), and each coefficient is calculated according to eq. (5)-(7).

$$
\begin{aligned}
C_{T} & =C_{F}+C_{R}+C_{A}+\Delta C_{F} \\
C_{F} & =\frac{0.075}{\left(\log _{10} R_{e}-2\right)^{2}} \\
C_{A} & =\left(5.86-0.6 \log R_{e}\right) \times 10^{-3} \\
\Delta C_{F} & =\left\{\left[44\left(\frac{A H R}{L_{P P}}\right)^{1 / 3}-10 \times R_{e}^{1 / 3}\right]+0.125\right\} \times 10^{-3}
\end{aligned}
$$

Above, $C_{T}$ is the total resistance coefficient, $C_{F}$ is the frictional resistance coefficient, which is calculated using the Reynolds number by eq. (5), and $C_{R}$ is the residual resistance coefficient, which is used to refer to the model test results. $C_{A}$ is the model-ship correlation factor and $\Delta C_{F}$ is the frictional resistance increase due to the surface roughness. $R_{e}$ is the Reynolds number and $L_{P P}$ is the length between perpendiculars.

The calculation results are listed in Table 6. The residual resistance coefficient is determined from towing tank test. $\Delta C_{F}$ is approximately $15 \%$ smaller than the $150 \mu m$ value considered as the hull roughness of a new ship. Also $C_{T}$ decreases by approximately $2 \%$.

Table 6 Total resistance calculation result depending on hull roughness

\begin{tabular}{|c|c|c|c|c|c|c|}
\hline $\begin{array}{c}\text { Velocity } \\
\text { (knots) }\end{array}$ & $\begin{array}{c}A H R \\
(\mu \mathrm{m})\end{array}$ & $\begin{array}{c}C_{F} \\
(\mathrm{E}-03)\end{array}$ & $\begin{array}{c}C_{R} \\
(\mathrm{E}-03)\end{array}$ & $\begin{array}{c}C_{A} \\
(\mathrm{E}-03)\end{array}$ & $\begin{array}{c}\Delta C_{F} \\
(\mathrm{E}-03)\end{array}$ & $\begin{array}{c}C_{T} \\
(\mathrm{E}-03)\end{array}$ \\
\hline \multirow{2}{*}{21} & 81 & \multirow{2}{*}{2.640} & 1.157 & 0.193 & 0.476 & 4.806 \\
\cline { 2 - 5 } & 150 & & & 0.558 & 4.888 \\
\hline
\end{tabular}

\section{Conclusion}

In this study, the hull roughness measurement was performed on the $160 \mathrm{~m}$ class car ferry using the hull roughness gauge of the TQC company, and the painting of the ship was completed before launching. For measurement, the entire area was divided into a total of 230 zones consisting of 102 zones on the sides (Port 51, Starboard 51) and 128 zones on the bottom area.

Consequently, the maximum and minimum $R_{t(50)}$ of the port and starboard areas were found to be measured similarly, but the $A H R$ showed approximately $20 \%$ difference. This was because the zones of the port area and starboard area were similar but could not perfectly match the measurement area. For the bottom area, the $R_{t(50)}$ and $A H R$ were relatively low compared to the values for the side areas (port and starboard), with the $A H R$ of the former being 
approximately $20 \%$ lower than the average of the side area. This was considered to be because the bottom area was relatively flat compared to the side areas.

The uncertainty of the measurement was analyzed according to ISO guidelines. The uncertainty of the measurement was analyzed by considering the standard uncertainty of the measurement values and equipment specification. Also these were combined using RSSM method and assuming a $95 \%$ confidence level. Finally, the $A H R$ of the ship by considering the uncertainty of the measurement was $81 \pm 8 \mu \mathrm{m}$, which was smaller than the hull roughness $(150 \mu \mathrm{m})$ proposed by the ISO guidelines [2]. However, it was in the roughness range from 80 to $150 \mu \mathrm{m}$ as suggested by Hudson et al. [18]. Using the measured $A H R, 81 \mu \mathrm{m}$, the resistance performance at the design speed of the ship was estimated, which showed that the total resistance was reduced by approximately $2 \%$ compared with the $A H R$ of $150 \mu m$ owing to the decrease in $\Delta C_{F}$.

As mentioned above, the measurement of the hull roughness of a ship is not an essential requirement. However, it should be performed to accurately estimate ship performance. This is because decreasing the hull roughness of a ship could reduce the ship's total resistance as this study shows. Also it is the one of best ways to reduce fuel oil consumption and carbon dioxide emission from vessel. However, once the ship is launched, there is no way to directly measure the hull roughness without dry-docking, so the measurement should be carried out before launch.

It is expected that the hull roughness of a new ship is lowered compared to that of past ships owing to the improvement in painting and painting skills. However, in this study, this makes it difficult to compare the hull roughness of this one ship with that proposed by the ISO considering various factors such as paint type and vessel type. Moreover, it is difficult to generalize the roughness of all ships using the roughness measurement of the ship performed in this study, and further measurement and related studies on various ship types and ships are required. However, in the future, we could expect that various studies will be performed based on the results of this measurement.

\section{ACKNOWLEDGEMENT}

This work was supported by the Technology Innovation Program (10063575, Accuracy enhancement of model-ship correlation based on the ship performance measurement, 20000721, Development of Autopilot applicated collision avoidance technology for medium and large vessel) funded by the Ministry of Trade, Industry \& Energy (MOTIE, Korea). It is noted that this paper involves some part of contents from a Ph. D. thesis of Pusan National University.

\section{REFERENCES}

[1] IMO., Third IMO GHG Study 2014, Executive Summary and Final Report. Retrieved from Suffolk, UK.

[2] ISO 15016; 2002., Ships and Marine Technology-Guidelines for the Assessment of Speed and Power Performance by Analysis of Speed Trial Data.

[3] Sulaiman, O., Saharuddin, A.H., Kader, A., and Samo, K.B., Qualitative method for antifouling long life paint for marine facilities or system, Biosci. Biotech. Res. Asia 7, no. 2, 675-688, 2010.

[4] Schultz, M.P., Frictional resistance of antifouling coating system, J. Fluids Eng., 126, no. 6, 1039-1047, 2004. https://doi.org/10.1115/1.1845552 
[5] Yeginbayeva, I.A., and Atlar, M., An experimental investigation into the surface and hydrodynamic characteristics of marine coatings with mimicked hull roughness ranges, Biofouling, 1-19, 2018. https://doi.org/10.1080/08927014.2018.1529760

[6] Demirel, Y.K., Khorasanchi, M., Turan, O., Incecik, A., and Schultz, M.P., A CFD model for the frictional resistance prediction of antifouling coatings, Ocean Eng., 89, 21-31, 2014. https://doi.org/10.1016/j.oceaneng.2014.07.017

[7] Tezdogan, T., Demirel, Y.K., Kellett, P., Khorasanchi, M., Incecik, A., and Turan, O., Full-scale unsteady RANS CFD simulations of ship behavior and performance in head seas due to slow steaming, Ocean. Eng., 97, 186-206, 2015. https://doi.org/10.1016/j.oceaneng.2015.01.011

[8] Seok, J., Park, J.C., Shin, M.S., and Kim, S.Y., A study on predicting ship resistance performance due to surface roughness using CFD, J. Soc. Naval Archi. Korea, 53, no. 5, 400-409, 2016. https://doi.org/10.3744/SNAK.2016.53.5.400

[9] Demirel, Y.K., Turan, O., and Incecik, A., Predicting the effect of biofouling on ship resistance using CFD, App. Ocean Res., 62, 100-118, 2017. https://doi.org/10.1016/j.apor.2016.12.003

[10] Owen, D., Demirel, Y.K., Oguz, E., Tezdogan, T., and Incecik, A., Investigating the effect of biofouling on propeller characteristics using CFD, Ocean. Eng., 159, 505-516, 2018. https://doi.org/10.1016/j.oceaneng.2018.01.087

[11] Farkas, A., Degiuli, N., and Martić, I., Towards the prediction of the effect of biofilm on the ship resistance using CFD, Ocean. Eng., 167, 169-186, 2018. https://doi.org/10.1016/j.oceaneng.2018.08.055

[12] Atencio, B. N., and Chernoray, V., A resolved RANS CFD approach for drag characterization of antifouling paints, Ocean. Eng., 171, 519-532, 2019. https://doi.org/10.1016/j.oceaneng.2018.11.022

[13] Speranza, N., Kidd, B., Schultz, M.P., and Viola, I.M., Modeling of hull roughness, Ocean Eng., 174, 31-42, 2019. https://doi.org/10.1016/j.oceaneng.2019.01.033

[14] Song, S., Demirel, Y. K., and Atlar, M., An investigation into the effect of biofouling on the ship hydrodynamic characteristics using CFD, Ocean. Eng., 175, 122-137, 2019. https://doi.org/10.1016/j.oceaneng.2019.01.056

[15] Seok, J., and Park, J. C., Numerical simulation of resistance performance according to surface roughness in container ships, International Journal of Naval Architecture and Ocean Engineering, 12, 11-19, 2020.

https://doi.org/10.1016/j.ijnaoe.2019.05.003

[16] TQC., TQC Hull roughness gauge DC9000 manual

[17] ITTC., ITTC Recommended Procedures and Guidelines: Full Scale Measurements Speed and Power Trials Hull and Propulsor Survey 2002

[18] Hudson, D.A., Molland, A.F., and Turnock, S.R., Ship Resistance and Propulsion: Practical Estimation of Propulsive Power. Cambridge University Press, 2014.

[19] ISO/IEC., ISO/IEC Guide 98-3:2008, Uncertainty of Measurement -Part 3 Guide to the Expression of Uncertainty in Measurement, 2008.

[20] Townsin, R.L., The ITTC Line - Its Genesis and Correlation Allowance, The Naval Architect, London, UK. 1985.

Submitted: $\quad$ 24.04.2019. Jun Seok, jseok@rims.re.kr

Research Institute of Medium \& Small Shipbuilding, Republic of Korea

Accepted: $\quad$ 11.03.2020. $\quad$ Corresponding author: Jong-Chun Park, jcpark@ @nu.edu

Department of Naval Architecture \& Ocean Engineering, Pusan National University 